Proceedings of the $9^{\text {th }}$ International Conference on Applied Informatics

Eger, Hungary, January 29-February 1, 2014. Vol. 2. pp. 329-336

doi: 10.14794/ICAI.9.2014.2.329

\title{
MAPPING: Exploration and identification of surrounding objects near Eszterhazy Karoly University of Applied Sciences
}

\author{
Tamás Gregus, András Perjési, Attila Szívós, Tibor Tajti, \\ Péter Magyar, Gábor Geda
}

Eszterhazy Karoly University of Applied Sciences

Mathematical and Informatical Institute

gregtom6@gmail.com, andris@aries.ektf.hu, attilaszivoswork@gmail.com,

tibor.tajti@gmail.com, magyarp@aries.ektf.hu, gedag@aries.ektf.hu

\begin{abstract}
Internet of Things has a lot of similar interpretation, but we get the most current, if we just summarize the attributes of that. It means the things can communicate with each other and with people. Furthermore, the objects detect their environment with sensors around them and they make choices based on this detection. In the recent past, new demands and expectations have appeared in our college. Different kinds of type events, foreigners came with Erasmus and Eger's tourism foreshow a necessity for technological renewal. With the usage of the above-mentioned term we can be able to make the navigation to be more dynamic. This effort would be perfect for a first significant appear of a new, tourist attracting technology in this city. This paper tries to describe our experiment in this topic.
\end{abstract}

Keywords: Internet of Things, Android, NFC, location marking, route planning

\section{Keystones of the concept development}

The Eszterhazy Karoly University of Applied Sciences and the Bay Zoltán Nonprofit Ltd. for Applied Research are working together in a project called TÁMOP4.2.2.C-11/1/KONV FutureRFID - Az RFID/NFC technológia továbbfejlesztési lehetőségei az „Internet of Things koncepciói mentén, where we use undermentioned terms. These are Internet of Things, Near Field Communication and Android. 


\subsection{Internet of Things}

The widest area from the mentioned terms is the Internet of Things (IoT) conception. Our project takes place inside that. It can be described in a lot of forms, but we get the most current if we just summarize its attributes. Specifically, the things can communicate with each other and with people, theremore the things can detect their environment and can make decisions according to these measurements [1].

With this scenario we should find good opportunities and, of course, devices to make the ideas to be real.

\subsection{New demands, expectations}

In the recent past new demands and expectations appeared in our college. Eger's tourism, the open days what frequently organized multiple times in every year, the Researcher's Night, the Museums' Night and other events, the foreigners came with Erasmus entries, the national conferences and sport events, the brazilian newcomers came by brazilian-hungarian interstate convention foreshow a necessity for technological renewal. Eger undergoes a transformation nowadays, so this rehabilitation is a good reason for other kind of innovation. That's why there would be need for more dynamic navigation on maps and for query of location positions, for the first significant appear of a new technology in Eger city. Important goals are route planning between two marks and touristic guidance near building and event localization.

\section{Assets}

\subsection{Near Field Communication}

In the above-mentioned project the research group called Hybrid Technologies searches ways for ordinary usages where we can combine Near Field Communication (NFC) with other technologies to be able to achieve better efficiency in solving of some kind of problems [2]. NFC gets very close to putting the world in your pocket. At September 5, 2002, Philips and Sony announced the definition of a next generation near field radio-frequency communication technology. As they said, it enables short-range communication networks between consumer devices incorporating an NFC interface, and it improves the way consumers exchange information between devices [3]. In a few words, NFC can serve as contactless payment system, it can be used for sharing contacts, videos, photos, files in the social network, playing multiplayer mobile games with each other, etc. Communication is possible either with NFC device or with an unpowered (passive) NFC chip (tag). Market researchers, such as IHS Technology showed us that NFC will be included in $64 \%$ of the mobile phones shipped in 2018 [4]. And in that time, Android will account for $75 \%$ of the NFC phone market. As IHS said "A major challenge for the NFC market in 2014 will be to develop services and applications that consumers want". Other important information is NFC was integrated $18.2 \%$ of the 1.5 billion 
phones shipped worldwide in 2013. These give proof of this technology is worth to deal with.

There are other, currently work-in-progress tasks of the research group worth mentioning. One of them is the Business Oriented Creature Identification (BOCI) project [5], where we try to combine cows and sensors, and the other one is making greater efficiency in the indoor localization, where we try to use NFC and sensors with the help of neural networks for guiding users inside of buildings. [6]
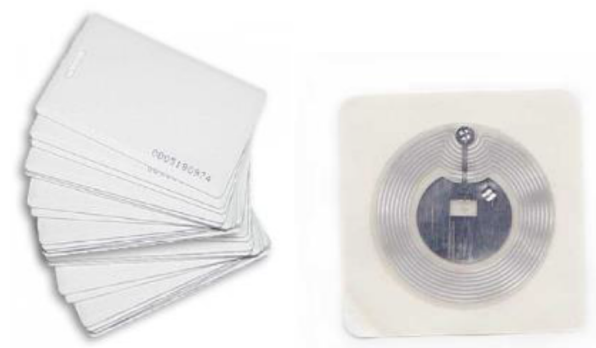

Figure 1: From left to right: NFC card tags, NFC stick tag

\subsection{Android}

NFC was a good choice because of that's an radio frequency identification (RFID) technology and the project is totally suits for that. With no exclude other opportunities, in the research we decided to choose smartphone platform. Because of their well-programmability and NFC support we chose the Android operating system, and with the help of the Android software development kit (SDK) and OpenNFC we could start to make applications for local interest and for general usage.

There were a lot of argue for Android. First of all, it is a mobile operating system based on the Linux kernel, designed to be on devices with touch screens (smartphones, tablets) [7]. NFC compatible version is existing since 2010 (with Android 2.3 Gingerbread, the android.nfc package was added in API level 9). The tools for development are given and well-baked (Android SDK), and some of the integrated development environments (IDE) are free (Eclipse, Android Studio early access preview version exists at the time of writing this paper). The platform and the application programming interface (API) dynamically improves, and not to mention that it has a documentation in excellent quality [8]. These attributes are favorable not only from the viewpoint of the project and research, but in educational usage it allows of the free getting of softwares, the teaching to be up-to-date and the smooth learning procedure (either in our college on lessons or for the students for preparation at home). For the project, what closes in 2014, another important viewpoint is that it should built on that kind of foundation, what ensures improvement opportunities in the future. A lot of market researcher (IDC, Gartner) showed the Android's superiority, what implicates that the Android's user society is a good basis of distributing applications. In Google Play 
store the applications supports NFC are constantly increase. In one survey, $76 \%$ of developers have already implemented or will implement NFC technology in their applications [9]. We try to implement some of ideas and functions what can't be found or can be only in smaller count what will be described later.

\section{Development}

As regards the development, we need to get access to the NFC function during the development for testing of the technology. Basically there are two methods known on the Android platform. First of them, we upload the code, what was compiled during the development, with an USB cable. Then we just simply run that on the target device. It's important to know that we get updates most frequently if we choose Google's own Nexus phone. It means that we get to access the newest API levels so we get the best hardware support. We have a Nexus 7 tablet PC, and a few Mifare Classic $1 \mathrm{~K}$ card, but also almost all of the developers have their own NFC mobile phones too. There are other companies who update their phones' software very quickly. In the following order: Motorola, Sony, Samsung, LG. If we want to get more chance to get official Android update if the certain phone is part of Android Open Source Project (AOSP). But the AOSP updates won't come from the original manufacturer, and there's a big chance that a few hardware elements won't work (just like with other custom roms). Other suggestion is to compile your own Android rom by yourself [10].

The other way is the IDE detects the previously started virtual device in the emulator running inside Android SDK, then as in the first method, the code will be uploaded into the virtual device and will be run there. Although Android SDK doesn't support the NFC hardware emulation at the moment, the NFC, as ability can be added to the virtual device. There's a solution in this case, it is manifested in OpenNFC framework (with an NFC Simulator and a Connection Center), developed by Inside Secure [11]. During the NFC communication, NFC Data Exchange Format (NDEF) messages has been instantiated by createMime() function, what can be used after API level 16, but with the help of OpenNFC we can write NFC supported, API level 17, Android 4.2.2 applications can be made. With the NFC Simulator, you can use tons of virtual tag types and you can check the connection's state. While programming, we should use the original class library's android.nfc and android.nfc.tech packages for reaching NFC function. Minimum requirement is API level 14 too, because it contains the Android Application Records (AAR) [12]. With the usage of that an application can be opened after reading the NFC tag. The package contains the application name should be inserted into an AAR record what will be placed into the NDEF message.

Further user requirement is to ensure the offline working near the online functions. When there's connection, newest information can be reached, in the case of offline working the lastly downloaded or the default messages can be seen. Furthermore, it is important to always follow the newest spread design patterns (for example navigation drawer [13]), and the newest working principles. We can use 
other technologies beside NFC, such as QR-code and GPS, what can be very helpful for locating positions. It is essential for take care of protection. We should ensure public and checked access on the user interface, and in the case of tags we should ensure the writing process only after authentication.

\section{Projects}

\subsection{Touristic guidance}

At this time the group works on multiple projects. One of them is a touristic guidance application, what will help in guidance of tourists came into Eger. The guidance can be happen by selecting locations on the map, or by previously programmed route plans. It would draw attention to actualities beside sights, like a newly opened restaurant, a menu action, or to a newness connected to a location. Besides this there would be a chance to leave messages just like in visitor's book, or get preference in certain shops, restaurants in Eger, after going-over a certain route. The application is based on NFC tags located in the city. If somebody wants to get information or preference, he/she should touch those spots word for word. Beside this application makes tourists' walk, who came into Eger to be more interactive, it would serve precise information and makes visitors to do local consumption. From the applications what can be found on Google Play store, the MTA SZTAKI Guide@Hand [14] or the TripAdvisor City Guide series [15] serves with similar functions, but all of them miss NFC support.

\subsection{EKC Message Wall}

The other line's goal is to make a College Message Wall. The application similarly based on the communication of NFC tags and phones with NFC capability. We place the NFC tags near rooms and offices and inside administrative room. The tags near teacher offices and inside administrative rooms are assigned to teachers (teacher tags), the tags near rooms are assigned to rooms (room tags). We implement the following functions in the application:

- Teacher message wall: it occurs that a teacher is searched when he/she is out of office. The student can leave message for him/her through a teacher tag.

- Actual tasks: when arriving into his/her office or into administrative room, the teacher can read not only the actual student messages, but also get notification from the daily important tasks.

- Attendance register and lesson studies: the student would be signed into the actual lesson's attendance register with a tag positioned near the room. This is how he/she can get information from the actual lesson study.

We think the above-mentioned functions are very important, because the information is forwarded at that moment when there is necessity for them. The student 
leave message at that time when he/she searched for the teacher, he/she attend to the certain lesson and get the lesson study when he/she is right there. The teacher gets notification from his/her tasks when he/she is arrived and when they must be done. He/She gets notification from the students questions and requests when he/she is right in the educational institute. The information flow will be fast and efficient in this way. We really targeted the application to suit for local and educational tasks so much, so we don't know any alternatives now.

\subsection{Navigation}

The third application helps the user navigation in those places where there isn't any GPS signal, but it's easy to get lost (for example in greater parking lots or inner spaces). The application navigates the user through locality spots with NFC tags towards the correct way. When creating the track according to the actual position the system takes security, speediness and other things defined by ourselves into consideration (for example ATM, an important stand in an expo, etc.). So we can find our car deep inside a big parking lot even if we had forgotten about the certain position of it, or we can find a stand in an expo if there is a big crowd and there're a lot of exhibitors. At the moment, SmartNavi [16], an application with similar goal available on Google Play, what follows our movement after a GPS positioning, according to our taken steps.
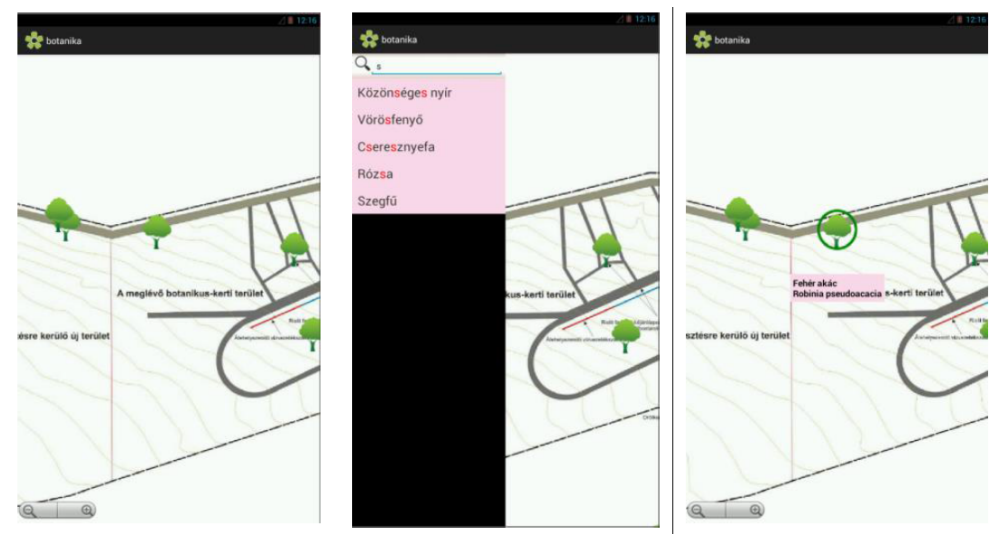

Figure 2: Images from the prototype application

\subsection{Concept of an universal NFC application}

Other idea would be to create a navigation system for Android phones based on information can be found on NFC tags. The main specialty is everybody can create maps for themselves about hotels, about history buildings, about museums, about anything what is have took in hand. The great thing is that the responsible person for creating the map and tags, positioning them, doing the maintenance is always 
been doing by the owner of the map, and the map serves for navigation and getting information for the public or for a closed society.

\section{Future scopes and ideas}

Thus the project's final goal is to make the principles of Internet of Things into practice; build an educational, applied platform, what found the currently developing and untapped technologies and implement the Internet of Things. There are a lot of tasks and objectives in front of us, what we will do with cooperation of students and teachers. We want to make a general platform for store information about collection, what would serve up-to-date data about the archived content and their position for maneuvering from one to the other. Just like an NFC-powered library.

We would like to use more and more technologies while doing these, near the Android and the NFC.

\section{References}

[1] KUSPER, G: A Survey of Internet of Things, 37th Conference of Teachers of Mathematics, Physics and IT (MAFIOK), Miskolc (2013)

[2] PERJÉSI, A; TAJTI, T; GEDA, G; MAGYAR, P; GREGUS, T: Using NFC and Other Integrated Devices in Android Smartphones For Development of Everyday Life Applications, 23rd International Conference on Computers and Education (SzámOkt), Nagyszeben (2013)

[3] Article about the Philips and Sony's strategic cooperation for define the NFC: http: //www. sony.net/SonyInfo/News/Press_Archive/200209/02-0905E/

[4] Forecast for world shipments of NFC handsets by IHS Technology: https://technology.ihs.com/490062/ nfc-enabled-cellphone-shipments-to-soar-fourfold-in-next-five-years

[5] TAJTI, T; GEDA, G; PERJÉSI, A; MAGYAR, P; BALLA, T; SZÍVÓS, A; GREGUS, T: Indoor localization using NFC and mobile sensor data corrected using neural net, 9th International Conference on Applied Informatics (ICAI), Eger (2014)

[6] MAGYAR, P; GEDA, G; TAJTI, T; PERJÉSI, A; GREGUS, T: Business Oriented Creature Identification, 9th International Conference on Applied Informatics (ICAI), Eger (2014)

[7] SIMON, S. Head First Android Development, O’Reilly Media, Inc.(2011), 4.

[8] Android API website for developers: http://developer.android.com/reference/ packages.html

[9] Survey, what contains that $76 \%$ of mobile developers want to use NFC in their apps: Evans Data Corporation: Mobile Developer Survey's Mobile Development Report

[10] YAGHMOUR, K., Embedded Android, O’Reilly Media, Inc. (2013) 
[11] VAZQUEZ-BRISENO, M., I. HIRATA, F., SANCHEZ-LOPEZ, J. de DIOS, JIMENEZ-GARCIA, E., NAVARRO-COTA, C., NIETO-HIPOLITO, J.I., Using RFID/NFC and QR-Code in Mobile Phones to Link the Physical and the Digital World, Interactive Multimedia, (2012), 229.

[12] COSKUN, V., OK, K., OZDENIZCI, B., Professional NFC Application Development for Android, John Wiley \& Sons, Ltd. (2013), 140.

[13] SMITH, D., FRIESEN, J., Android Recipes: A Problem-Solution Approach: Third Edition, Apress Medial, LLC., (2014), 248.

[14] MTA SZTAKI Guide@Hand: http://www.guideathand.com/

[15] TripAdvisor City Guide: http://www.tripadvisor.com/apps

[16] SmartNavi:

https://play.google.com/store/apps/details?id=com.ilm.sandwich 